\title{
Endoscopic obliteration of fundal varices
}

\author{
N SOEHENDRA, MD, H GRIMM, MD, A MAYDEO, MD, VCh NAM, MD, \\ B ECKMANN, MD, M BRUCKNER, MD
}

\begin{abstract}
In cases of portal hypertension, the fundus of the stomach is second to the esophagus as the most likely area for varices, at a frequency of about $10 \%$ in all patients having esophageal varices. It is relatively rare, probably due to the individual vascular anatomy rather than the level of portal pressure. The authors' experience shows that fundal varices appear more frequently with prehepatic block than intrahepatic. Can J Gastroenterol 1990;4(9):643-646 Key Words: Endoscopic obliteration, Fundal varices

\section{Obturation endoscopique des varices fundiques}

RESUME: En cas d'hypertension portale, le fundus de l'estomac est, après l'oesophage, la région la plus sujette à la survenue des varices. La fréquence est d'environ $10 \%$ chez tous les patients atteints de varices oesophagiennes. Cette rareté relative est probablement attribuable à l'anatomie vasculaire individuelle plutôt qu'au degré de pression portale. D'après notre propre expérience, les varices fundiques font plus fréquemment suite à une obstruction préhépatique que intrahépatique.
\end{abstract}

\section{IN}

IN CASES OF PORTAL HYPERTENSION, the fundus of the stomach is second to the esophagus as the most likely area for varices, at a frequency of about $10 \%$ in all patients having esophageal varices. It is relatively rare, probably due to the individual vascular anatomy rather than to the level of portal pressure. The authors' experience shows that fundal varices appear more frequently with prehepatic block than intrahepatic.

Occasionally fundal varices appear in an esophagus which has no varices. The cause is usually a segmental prehepatic block obliterating only the splenic vein. A blockage of splenic bloodflow causes fundal varices to form over the short gastric veins as the main collaterals. As a rule, splenomegaly develops at the same time. Thrombosis of the splenic vein as a cause of segmental prehepatic block has a multifarious etiology. Usually, however, it is a case of a diseased spleen or pancreas. Trauma of the spleen or chronic pancreatitis is most frequently observed.

Until now surgery was the main treatment for fundal varices. Endoscopic sclerotherapy by conventional means did not produce satisfactory results and was associated with an overwhelming recurrence rate. Varices located at the gastric fundus are usually large calibre and convoluted. Endoscopically, they often appear to be polypous with the result that they are mistaken as polyps and removed accordingly. Large varices cannot be sclerosed with conventional sclerosing agents in just a few sessions. Following sclerotherapy, massive erosion bleeding from mucosal necrosis occurs if varices are still open.

Surgical treatment is also difficult. Patients suffering from decompensated hepatic disease with acute recurrent bleeding from fundal varices present a special problem. The wide range of 


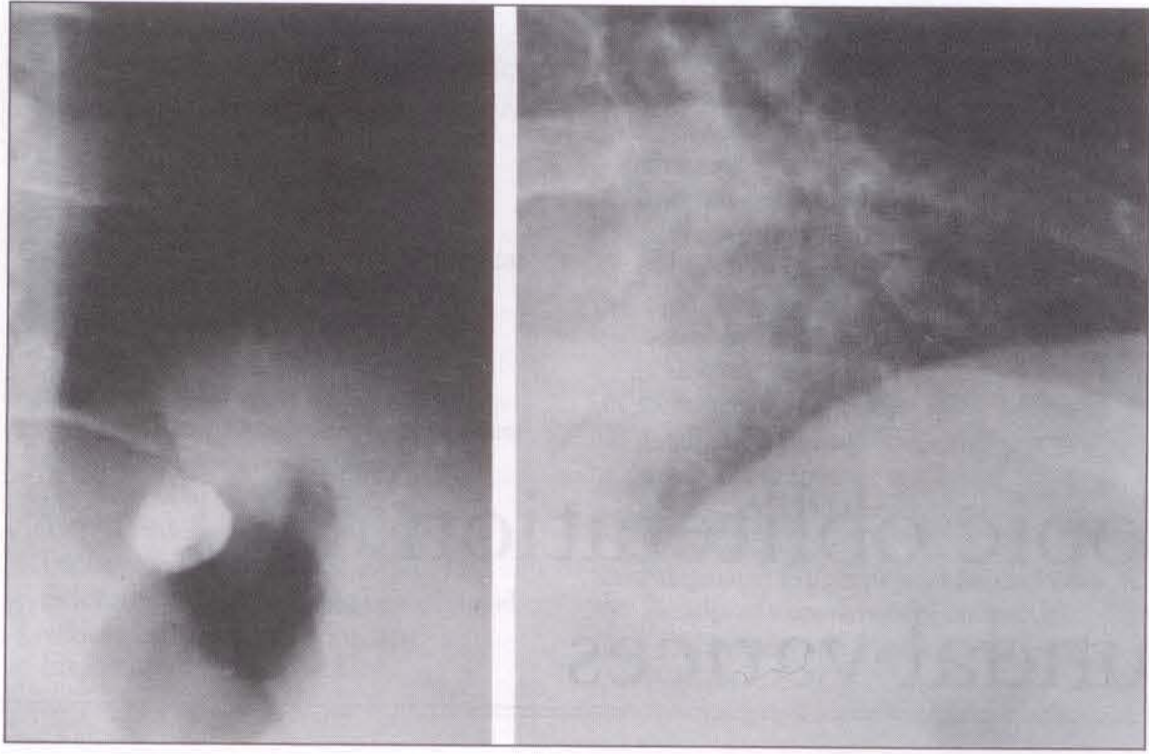

Figure 1) Left $X$-ray picture documenting injected tissue adhesive in the fundal varix. Right $X$-ray picture showing disappearance of the tissue adhesive after about two months

methods extend from local ligatures and devascularization to fundectomy; unfortunately, the stress of these methods is too great for a patient in the acute stage to bear. In 1985 the authors initiated in their hospital the use of the tissue adhesive n-butyl-2-cyanoacrylate for endosatipic obliteration of fundal varices (1). Since then 128 patients have been treated in this manner. Over the same period of time the tissue ad- hesive was used just as successfully to treat variceal bleeding in the esophagus. As a result, the hospital mortality for patients presenting with acute recurrent hemorrhage fell from 31.5 to $14.5 \%(2)$.

\section{METHODS}

Endoscopically, it is best to visualize and approach fundal varices in retroversion. Retroversion is easily achieved by rotation of both operating wheels in order to bend the tip of the endoscope as far as possible. More powerful air insufflation is necessary for optimal visualization of the varices at the gastric fundus. A forward viewing fibrescope with a working channel of at least $3.7 \mathrm{~mm}$ which offers sufficient suction it recommended.

The tissue adhesive (Histoacryl, Braun-Melsungen, Germany) is a watery liquid which can be injected through the usual injection catheter having a $0.7 \mathrm{~mm}$ needle. This solution solidifies by polymerization upon contact with blood and within $20 \mathrm{~s}$ in a moist condition. In order to prevent premature solidification, the tissue adhesive is mixed with ethiodized oil (Lipiodol; Therapex) in a ratio of $0.5: 0.8 \mathrm{~cm}^{3}$. Another advantage of mixing the adhesive with the contrast medium is that it provides a basis for fluoroscopic checks.

The injection should be done quick. ly. The authors use $2 \mathrm{~cm}^{3}$ plastic syrin. ges. During acute bleeding, the needle of the injection catheter is retracted a few centimetres so that the distal part of the catheter can be kept blood free by constant instillation of distilled water. Distilled water is more compatible with Histoacryl than
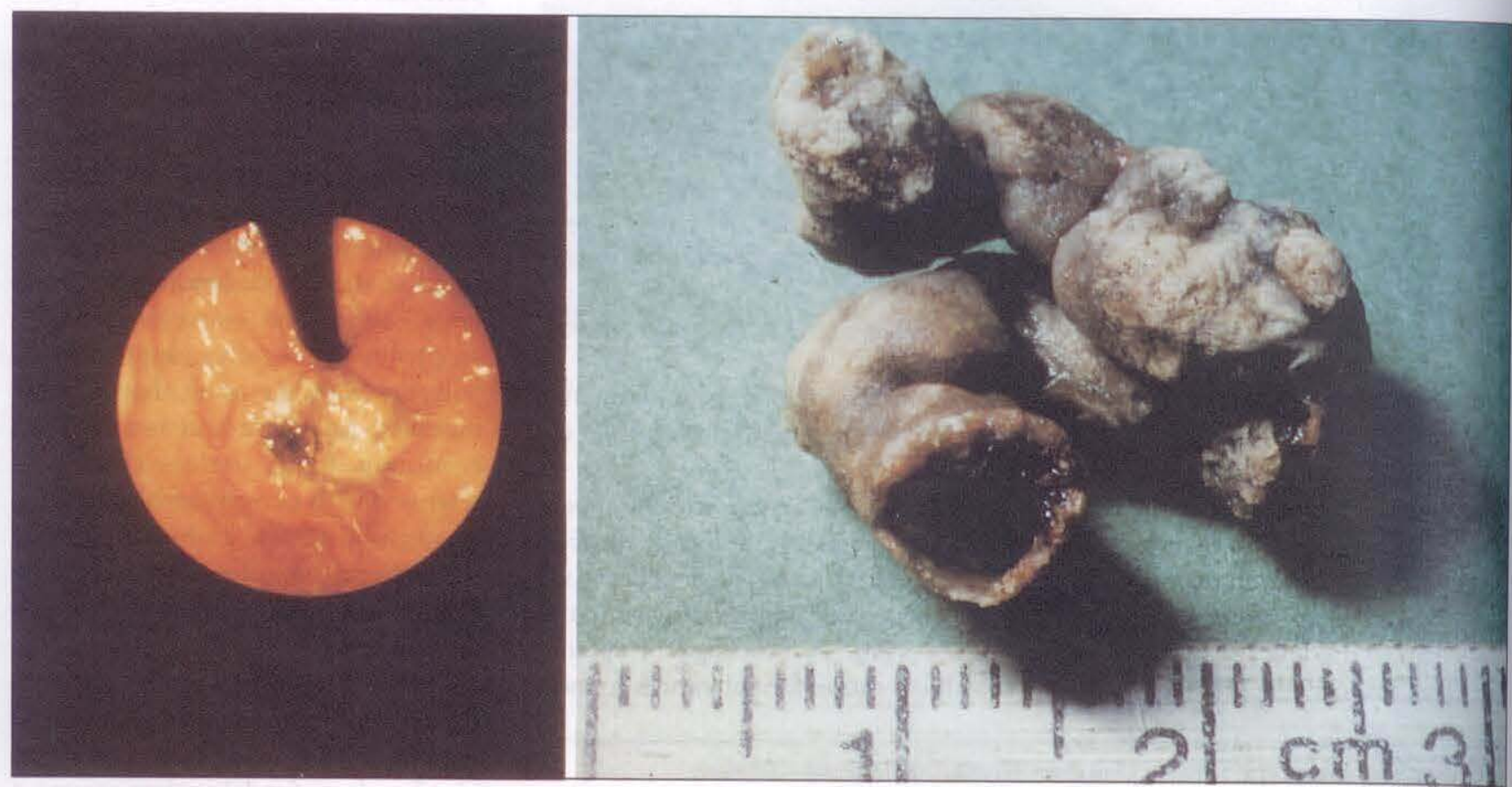

Figure 2) Left Endoscopic appearance of the solid tissue adhesive sloughing out of the obliterated varix. Right The sloughed off solid tissue adhesive as seen in vitro and shaped like a venous cast 
physiological sodium chloride solution. Immediately after puncturing of the varix, the intravascular position of the needle can be confirmed by means of pre-injection with sterile water. A perivascular injection would cause immediate submucosal swelling.

As a rule, large fundal varices require approximately $2 \mathrm{~cm}^{3}$ HistoacrylLipiodol mixture in all. However, each individual injection should not contain more than $0.5 \mathrm{~cm}^{3}$ in order to avoid embolism. Since the injection catheter holds about $0.7 \mathrm{~cm}^{3}$, a corresponding amount of distilled water must be injected immediately after the tissue adhesive. The needle is then immediately retracted, and the catheter is continually rinsed with water in order to keep it free and ready for the next injection. Suction should not be done throughout the entire procedure. The injection catheter may be retracted from the endoscope not earlier than $20 \mathrm{~s}$ following injection. Applying silicone oil or Lipiodol prevents anything sticking to the endoscope. For the same purpose, oil is drawn up through the working channel. Any adhesion in the working channel can be removed at once with a brush.

Polypoid fundal varices usually have several branches. It is important to tackle all of the veins during obliteration in order to avoid recurrent bleeding. Obliterated varices feel firm and the results of treatment can be checked easily by touching them with the catheter. The $\mathrm{x}$-ray image provides

\section{TABLE 1}

Distribution of age and sex of 128 patients diagnosed endoscopically as having fundal varices

\begin{tabular}{cccc}
\hline $\begin{array}{c}\text { Age } \\
\text { (years) }\end{array}$ & Female & Male & $\begin{array}{c}\text { Percent- } \\
\text { age }\end{array}$ \\
\hline $0-9$ & - & 1 & 0.8 \\
$10-19$ & 2 & 6 & 6.2 \\
$20-29$ & 0 & 1 & 0.8 \\
$30-39$ & 3 & 4 & 5.5 \\
$40-49$ & 12 & 20 & 25.0 \\
$50-59$ & 8 & 26 & 26.6 \\
$60-69$ & 8 & 24 & 25.5 \\
$70-79$ & 5 & 6 & 8.6 \\
$80-89$ & - & 2 & 1.5 \\
Total & 38 & 90 & 100.0 \\
\hline
\end{tabular}

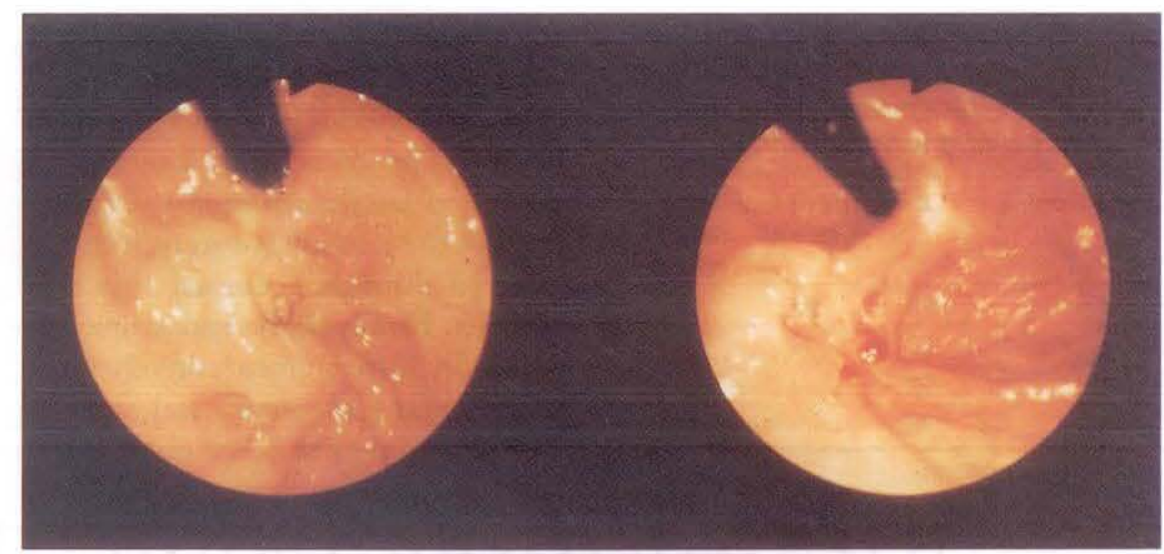

Figure 3) Endoscopic appearances of obliterated gastric varices after extrusion of the solid tissue adhesive, now in the healing stage

\section{TABLE 2}

Causes of portal hypertension and frequency of fundal varices in 128 patients diagnosed endoscopically as having fundal varices

\begin{tabular}{lccr}
\hline $\begin{array}{l}\text { Causes of portal } \\
\text { hypertension }\end{array}$ & Number of patients & Percentage & $\begin{array}{c}\text { Frequency among } \\
\text { total population }\end{array}$ \\
\hline Liver cirrhosis & 75 & 58.7 & $75 / 720=10.4 \%$ \\
$\quad \begin{array}{l}\text { Alcohol } \\
\text { Hepatitis }\end{array}$ & 22 & 17.2 & $22 / 222=9.9 \%$ \\
Unkown/others & 12 & 9.4 & $12 / 112=10.7 \%$ \\
Prehepatic block & 12 & 9.4 & $12 / 45=26.6 \%$ \\
Others & 7 & 5.4 & $7 / 50=14.0 \%$ \\
Total & 128 & & $128 / 1149=11.1 \%$ \\
\hline
\end{tabular}

documentation of this procedure (Figure 1).

Approximately one week later, the mucosa over the obliterated varices visibly begins to slough off. Several months sometimes elapse before the solidified tissue adhesive is expelled through the sloughed off mucosa (Figure 2). Regular endoscopic and radiologic checks help to monitor further progress (Figure 3). Special follow-up treatment is not necessary.

\section{RESULTS}

From 1985 to 1990 the authors have diagnosed fundal varices endoscopically in 128 patients. There were 90 males and 38 females between nine and 82 years old. The distribution according to age (Table 1) shows that the greatest number of patients were between 40 and 60 years old. Cirrhosis of the liver was the main cause of portal hypertension at $85.3 \%$; the rate of prehepatic block was only $9.4 \%$. Fundal varices were found in $11.1 \%$ of all patients who were treated endoscopically for varices in the past 11 years. Considering the number of fundal varices found in the various causes of portal hypertension, it can be concluded that prehepatic block most frequently caused fundal varices (Table 2).

Of the 128 patients with fundal varices, 23 were treated endoscopically during an acute stage. All bleeding could be controlled immediately with tissue adhesive. Fifty-seven were treated during the interim for recurrent bleeding from the varices. The remaining 10 underwent prophylactic obliteration therapy, because their varices appeared too large. Two patients undergoing treatment during the interim suffered recurrent bleeding during hospitalization. This event corresponds to an early recurrence rate of $2.2 \%$. No patient died of bleeding (Table 3).

Within the five year observation period, five patients suffered recurrent hemorrhage from newly formed fundal 
TABLE 3

Results of endoscopic obliteration in 90 patients diagnosed endoscopically as having fundal varices

\begin{tabular}{lccc}
\hline Treatment & $\mathbf{n}$ & $\begin{array}{c}\text { Hemo- } \\
\text { stasis }\end{array}$ & $\begin{array}{c}\text { Early } \\
\text { recur- } \\
\text { rence }\end{array}$ \\
\hline Acute & 23 & 23 & - \\
Interval & 57 & - & 2 \\
Prophylactic & 10 & - & - \\
Total & 90 & & $2=2.2 \%$ \\
\hline
\end{tabular}

$n$ Number of patients

varices. The late recurrence rate for this period was therefore $5.5 \%$. No mortality due to recurrent bleeding was observed.

\section{DISCUSSION}

According to the authors' experience, the liquid tissue adhesive $n$ butyl-2-cyanoacrylate is an excellent substance for obliterating fundal varices. A $0.5 \mathrm{~cm}^{3}$ mixture with Lipiodol is sufficient to obliterate a varix. Usually three to four injections are required for large variceal convolutes. Based on numerous radiological control checks, it appears that there is no danger of an embolism from a single dose less than or equal to $0.5 \mathrm{~cm}^{3}$. Because the solution is watery, it can be injected through a normal injection catheter. However, the endoscopic application differs from conventional sclerotherapy of esophageal varices. The injection must be precisely intravascular and must progress very quickly, since it entails obliteration using a quickly solidifying substance. There is no danger of sticking to an endoscope which has been prepared with silicone oil or Lipiodol before hand. However, the injection catheter can occlude very quickly. Often a catheter is good for one single injection.

Endoscopic obliteration therapy with tissue adhesive has made real progress not only in treatment of large fundal varices but also in control of variceal bleeding. It has made endoscopic hemostasis a safe and sure method of treatment. Early recurrent bleeding from esophageal varices has been reduced by more than half; hospital mortality has dropped accordingly (2).

Large fundal varices, formerly in want of adequate treatment, can now be obliterated endoscopically in one ses. sion with satisfactory long term results $(3,4)$.

\section{REFERENCES}

l. Soehendra N, Nam VC, Grimm H, et al. Endoscopic obliteration of large esophagogastric varices with bucrylate Endoscopy $1986 ; 18: 25-6$

2. Soehendra N, Grimm H, Nam VC, et al. 10-Jahres-Erfahrung mit der endoskopischen Sklerotherapie von oesophagogastrischen Varices. Chirurg 1989;60:594-8.

3. Soehendra N, Grimm H, Nam VC, et al. N-Butyl-2-Cyanoacrylate: A sup. plement to endoscopic sclerotherapy. Endoscopy 1987;19:221-4

4. Ramond MJ, Valla D, Mosnier JF, et al. Successful endoscopic obturation of gastric varices with butyl cyanoacry. late. Hepatology 1989;10:488-93. 


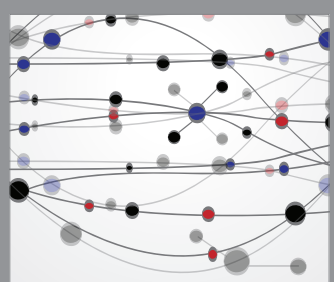

The Scientific World Journal
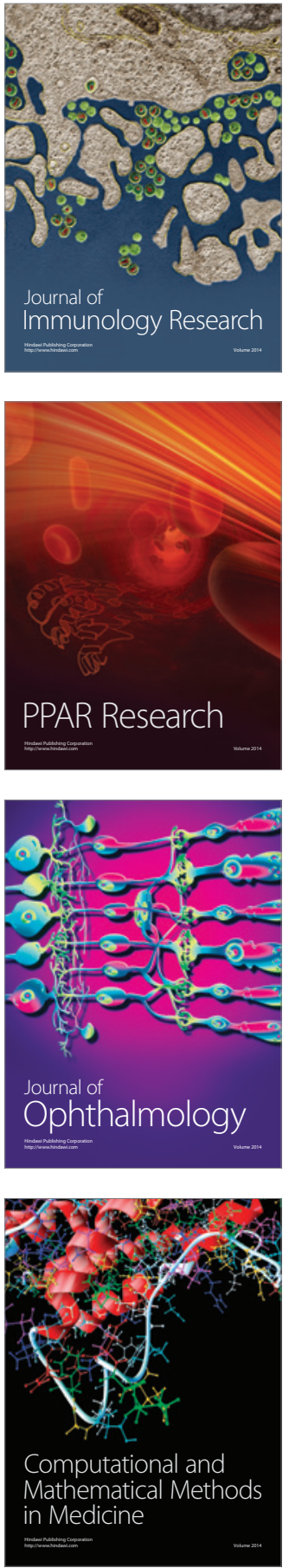

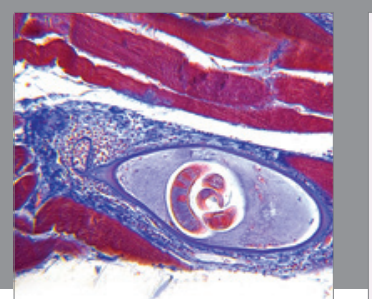

Gastroenterology Research and Practice

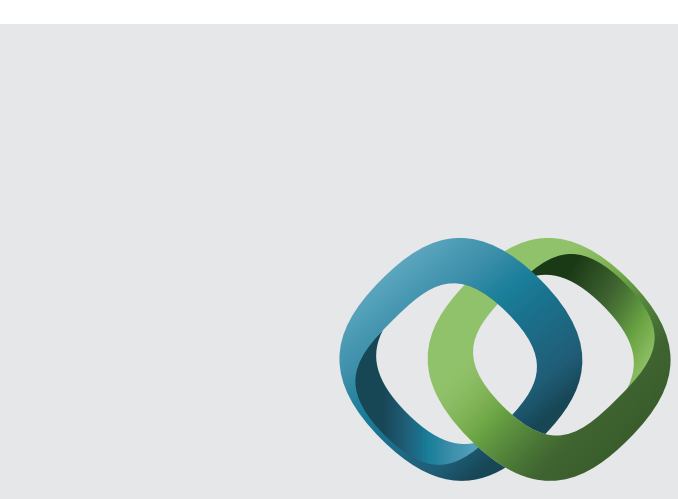

\section{Hindawi}

Submit your manuscripts at

http://www.hindawi.com
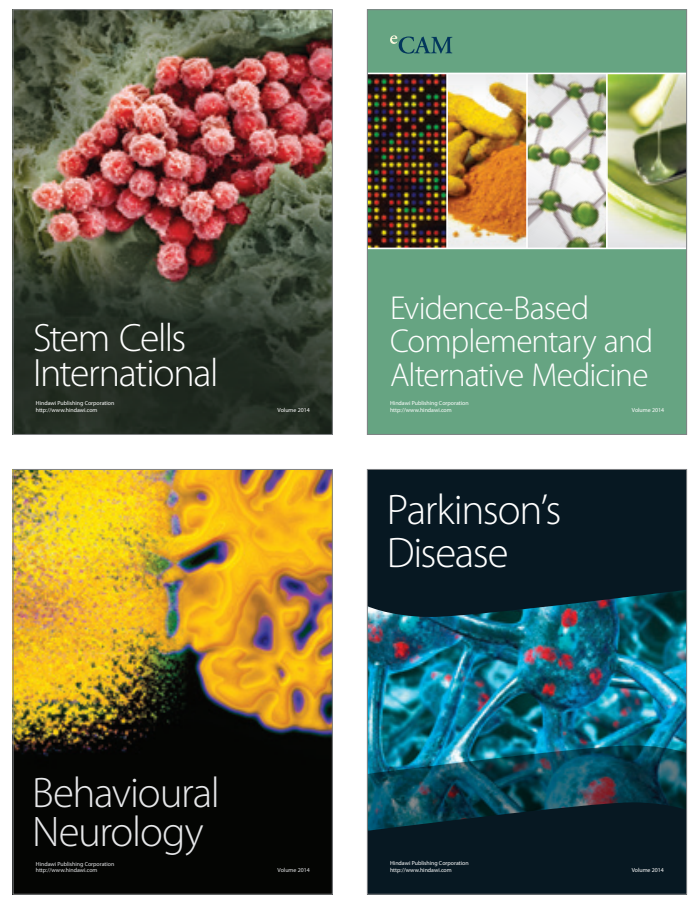
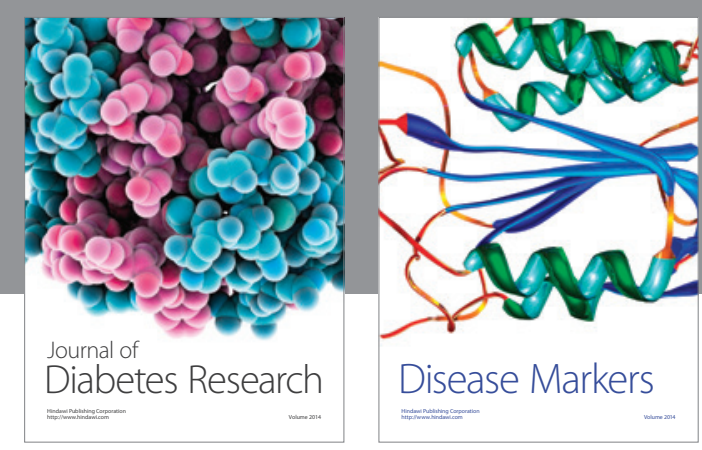

Disease Markers
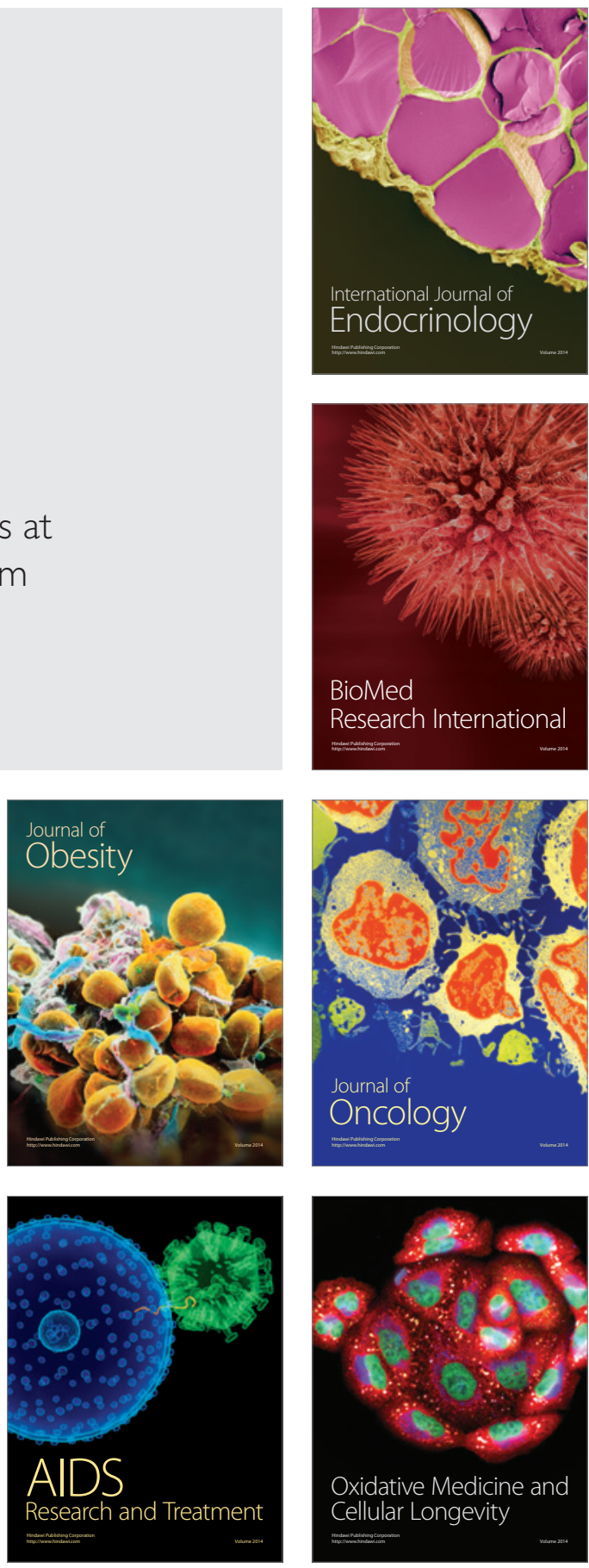